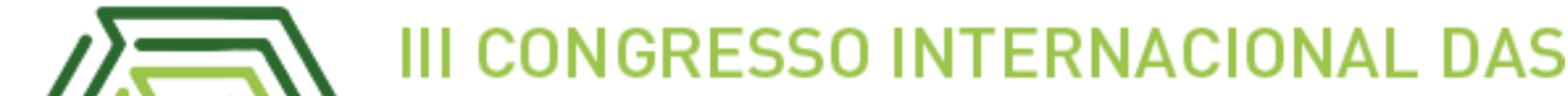 CIÊNCIAS AGRÁRIAS COINTER - PDVAGRO 2018
}

\section{CARACTERIZAÇÃO DO CULTIVO DE JAMBU NAS REGIÕES PRODUTORAS DE HORTALIÇAS QUE ABASTECEM O MUNICÍPIO DE CASTANHAL}

\section{CHARACTERIZATION OF JAMBU CULTIVATION IN THE REGIONS PRODUCING VEGETABLES SUPPLYING THE MUNICIPALITY OF CASTANHAL} Apresentação: Pôster

Mizael Cardoso da Silva ${ }^{1}$; Carlos Anderson Sousa de Carvalho²; Flávio Sampaio Mendes $^{3}$; Nalton Enderson Silva da Silva ${ }^{4}$; Gilberta Carneiro Souto ${ }^{5}$

\section{DOI: https://doi.org/10.31692/2526-7701.IIICOINTERPDVAGRO.2018.00364}

\section{Introdução}

O jambu (Acmella oleracea), é uma hortaliça de largo consumo no estado do Pará. Além de fazer parte de comidas típicas regionais, como o pato no tucupi e o tacacá, vem sendo utilizado de forma mais geral, seja em saladas ou compondo outros pratos. Sua composição química, incluindo o espilantol, têm potencial para uso industrial, sendo ainda citado como indicativo para diversas doenças (GUSMÃO et al, 2009).

É uma hortaliça bastante cultivada e consumida, sendo sua maior demanda nos períodos festivos, tais como o Círio de Nazaré e as festas de fim de ano. Popularmente essa planta também é utilizada como erva medicinal, pois segundo os dizeres populares suas folhas e flores podem ser recomendadas para elaboração de infusões no tratamento de anemia, dor de dente e garganta, sendo sugerido como antibiótico e anestésico (BORGES et al, 2013).

Dezenas de produtores cultivam jambu na região produtora de hortaliças que abastece o município de Castanhal. Devido a importância que essa hortaliça representa, é necessário um diagnóstico da forma com que o cultivo vem se desenvolvendo, de forma a propor ações de pesquisa ou de apoio imediato, caso haja obstáculo ao cultivo.

\footnotetext{
${ }^{1}$ Graduando em Agronomia e Bolsista PET Agronomia, Instituto Federal do Pará - Campus Castanhal, mizaelsilva-13@hotmail.com

${ }^{2}$ Graduando em Agronomia e Bolsista PET Agronomia, Instituto Federal do Pará - Campus Castanhal, anderson_casc@hotmail.com

${ }^{3}$ Graduando em Agronomia, Instituto Federal do Pará - Campus Castanhal, flavio.ifpa2014@gmail.com,

${ }^{4}$ Graduando em Agronomia, Instituto Federal do Pará - Campus Castanhal, naltonendersonsilva@gmail.com

${ }^{5}$ Professora EBTT, Instituto Federal do Pará - Campus Castanhal, gilberta.souto@ifpa.edu.br
} 
Diante do exposto, o trabalho teve como objetivo conhecer a forma atual de cultivo de jambu nas regiões produtoras de hortaliças que abastecem o município de Castanhal e identificar pontos atuais e futuros que possam comprometer a produção.

\section{Metodologia}

A pesquisa foi realizada em Castanhal e municípios próximos, onde concentram-se uma grande quantidade de produtores de hortaliças. O procedimento metodológico usado foi de natureza quantitativa e consistiu na aplicação de questionário semiestruturado com perguntas abertas e fechadas.

Foram entrevistados, no período de outubro de 2015 a julho de 2016, 34 produtores de hortaliças, cultivando jambu, e feito visitas às respectivas propriedades. Dentre as informações requeridas, buscou-se saber a origem das sementes, forma de semeadura e condução do plantio, ocorrência de pragas e doenças, formas de controle e rendimento do cultivo.

Os produtores caracterizaram-se por cultivarem hortaliças convencionais e nãoconvencionais, com destaque para alface, couve, coentro, cebolinha, maxixe, chicória, abóbora e jambu, utilizarem preferencialmente mão-de-obra familiar e destinarem quase toda a produção para o mercado de Castanhal.

Os dados coletados nos pontos que permitiam e foram avaliados, em termos de percentagem de ocorrência, usando o Excell.

\section{Resultados e Discussões}

Foram identificados 9 pontos de produção de hortaliças que abastecem o município de Castanhal: km 07 (Curuçá), km 48 (São Francisco), km 23 (Santa Maria), km 37 (São Miguel do Guamá), Areia Branca (setor produtivo de hortaliças, pertencente ao município de Santa Isabel), Agrovila de Iracema, Agrovila do Calúcia, comunidade do Barreirão e Agrovila Caranã em Castanhal.

Quanto a origem das sementes, os dados estão expostos no gráfico abaixo: 


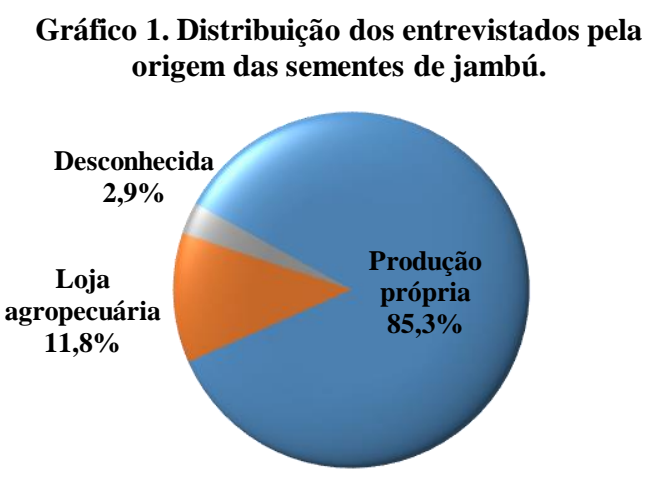

85,3\% dos produtores obtém as sementes na própria área, em canteiros, cuja finalidade é a produção de sementes. $11,8 \%$ adquirem as sementes em casas agropecuárias e 2,9\% desconhecem a origem das sementes. Resultados semelhantes foram obtidos por Silva et al (2016), que identificaram 78\% dos olericultores obtendo as sementes de jambu na própria área, deixando periodicamente canteiros para produção de sementes, $18 \%$ dos produtores obtêm sementes nas casas agropecuária, obtidas quando iniciaram a atividade com jambu e 4\% desconhecem a origem das sementes. Gusmão et al (2009), a totalidade dos olericultores obtém as sementes na própria área, deixando periodicamente canteiros para produção de sementes. A origem das sementes é de outras áreas produtoras, obtidas quando iniciaram a atividade olerícola.

Com relação a forma de semeadura e condução do plantio:

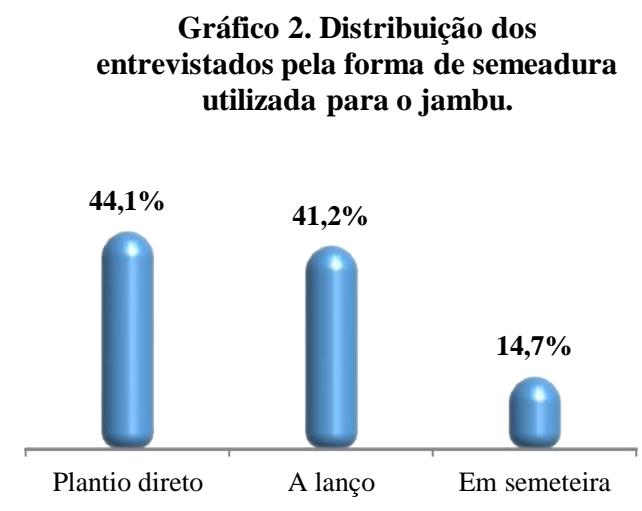

44,1\% dos entrevistados fazem o plantio direto nos canteiros, colocando-se de 5 a 10 sementes por unidade de área. A semeadura a lanço é realizada por 41,2\%, com alta concentração de sementes. A semeadura em sementeira é feita por 14,7\%, na qual, coloca-se de 5 a 10 sementes por unidade e feito o desbaste antes do transplantio para o local definitivo. $\mathrm{O}$ plantio direto e a semeadura em sementeira são realizadas pelos produtores que obtiveram 
algum tipo de treinamento. Os ramos podem ser usados para propagar as plantas, e podem ser plantados em solo mantido bem úmido até que ocorra o enraizamento (HORTAS.INFO, 2018). Embora seja planta de fácil propagação através de ramos, nenhum produtor utiliza a multiplicação assexuada (PIMENTEL,1985).

$73,5 \%$ dos produtores cultivam jambu o ano todo, enquanto $26,5 \%$ só plantam próximo as datas festivas, como o círio de São José (padroeiro do município de Castanhal), círio de $\mathrm{N}^{\mathrm{a}}$ Sra. de Nazaré e natal. Todos os produtores entrevistados fazem uso de irrigação, onde predomina a irrigação por santenos, com água bombeada de poços artesianos e rios. De acordo com Silva et al (2016), todos os produtores fazem irrigação através de mangueiras, santenos, bicos e aspersão, com água bombeada de poços artesianos. Por se tratar de uma planta folhosa e devido às condições climáticas com temperaturas elevadas na região de cultivo, a irrigação é indicada duas vezes ao dia (BATISTA et al, 2016).

Quanto a adubação, todos os produtores fazem uso de adubos orgânicos, utilizando a cama de aviário, com 73,5\% utilizando apenas adubos orgânicos e 26,5\% usando adubos orgânicos e conjunto com o adubo químico. Na adubação de plantio é utilizada cama de aviário, sendo também usada em cobertura, duas a três vezes durante o ciclo de cultivo (SILVA et al, 2016). Para Souto (2016), o melhor desempenho agronômico do jambu foi obtido com a aplicação de $10 \mathrm{~kg} \mathrm{~m}-2$ do adubo orgânico, com maior produtividade no cultivo realizado de maio a junho de 2015 .

Dentre as pragas que atacam o jambu, 73,5\% citaram a lagarta falsa-medideira (Pseudoplusia includens), 11,8\% a paquinha (Gryllotalpa gryllotalpa)5,9\% a lesma (Vaginulus sp), 5,9\% a cigarrinha (Empoasca kraemeri) e 2,9\% o grilo (Acheta domesticus). Resultado diferente foi obtido por Gusmão et al (2009), onde todos os produtores citaram a paquinha (Neocurtilla hexadactyla) como principal praga. Para Silva et al (2016), todos os produtores citaram a paquinha e a lagarta falsa-medideira, como principais pragas. Não foram identificadas doenças nos plantios. O jambu possui grande adaptação regional e rusticidade, com poucos registros de ataque de pragas e doenças e baixa índice de uso de controle (BATISTA, 2016).

No combate as pragas, $81,3 \%$ dos entrevistados fazem uso de produtos químicos, com destaque para deciz e cipitryn, e apenas $19,7 \%$ fazem uso de iscas e armadilhas, com exceção da lesma, que não é feito combate. De acordo com Gusmão et al (2009), o controle é efetuado por uso de iscas a base de farelo de trigo e um inseticida. Esse inseticida varia entre áreas de produtores, predominando organofosforados e carbamatos. Para Silva et al (2016), o controle é 
efetuado por uso de iscas a base de farelo de trigo e um inseticida. Esse inseticida varia entre áreas de produtores, predominando cipitryn e deciz.

A colheita ocorre quando inicia a floração, podendo ser retardada ou antecipada em função do mercado. No rendimento do cultivo, em média, são 220 maços por canteiros e a quantidade de maços por $\mathrm{m}^{2}$ variou de 8 a 11 maços, pesando de 400 a 450 gramas. Gusmão et al (2009) encontraram rendimento variando de seis a dez maços por $\mathrm{m}^{2}$ de canteiro e os maços variando de 300 a $500 \mathrm{~g}$.

\section{Conclusões}

A introdução de sementes de origens desconhecidas ou provenientes de casas agropecuárias tem gerado plantas com grau de dormência inferior, o que tem sido alvo de críticas pelos consumidores.

A conscientização dos produtores quanto ao uso de Equipamentos de Proteção Individuais (EPIs), a dosagem adequada do produto, intervalo de aplicações, tempo de carência, é de suma importância para se avançar nesta questão, pois muitos deles recebem orientação, mas não fazem uso da mesma.

A abertura de novos mercados e o investimento em pesquisa que elevem o consumo de jambu podem alavancar a produção.

\section{Referências}

BATISTA, M. G. Períodos de interferência e manejo de plantas daninhas no cultivo de jambu (Acmella Oleraceae). Mossoró - RN, 2016. 49p. Tese (Manejo de Plantas Daninhas). Programa de Pós-Graduação em Fitotecnia Doutorado em Fitotecnia, UFERSA, 2016

BORGES, L. S.; GUERRERO, A. C.; GOTO, R.; LIMA, G. P. P. Produtividade e acúmulo de nutrientes em plantas de jambu, sob adubação orgânica e mineral. Semina: Ciências Agrárias, Londrina, v. 34, n. 1, p. 83-94, jan./fev. 2013

GUSMÃO S. A. L.; GUSMÃO M. T. A.; SILVESTRE W. V. D.; LOPES P. R. A. caracterização do cultivo de Jambu nas áreas produtoras que abastecem a grande Belém. In: CONGRESSO BRASILEIRO DE OLERICULTURA, 49, 2009, Águas de Lindóia. Resumos... Águas de Lindóia: CBO, 2009. Versão eletrônica.

HORTAS.INFO. Como plantar jambu. 2018. Disponível em: https://hortas.info/como-plantarjambu

PIMENTEL, A.A.M.P. Olericultura no trópico úmido: hortaliças na Amazônia. São Paulo. Ed. Ag. Ceres, 1985. 322p. 
SILVA, M. C.; CAVALCANTE, A. E. C.; FERREIRA, C. P.; SOUTO, G. C. Caracterização da cadeia produtiva do jambu no município de Castanhal - PA. In: VIII Seminário de Iniciação Científica, Tecnológica e Inovação, 2016, Castanhal - PA. Anais da VIII Seminário de Iniciação Científica, Tecnológica e Inovação, 2016.

SOUTO, G. C. Desempenho agronômico e acúmulo de nutrientes pela planta de jambu. Mossoró - RN, 2016. 48p. Tese (Práticas culturais). Programa de Pós-Graduação em Fitotecnia Doutorado em Fitotecnia, UFERSA, 2016 